CLINICAL STUDY

\title{
Serum sex hormone and plasma homocysteine levels in middle- aged and elderly men
}

\author{
Hamid Reza Nakhai Pour ${ }^{1}$, Diederick E Grobbee ${ }^{1}$, Majon Muller ${ }^{1}$, Marielle Emmelot-Vonk ${ }^{2}$ and Yvonne T van der \\ Schouw $^{1}$ \\ ${ }^{1}$ Julius Center for Health Sciences and Primary Care and ${ }^{2}$ Department of Geriatrics, University Medical Center Utrecht, STR 6.131, PO Box 85500, 3508 \\ GA Utrecht, The Netherlands \\ (Correspondence should be addressed to Y T van der Schouw; Email: y.t.vanderschouw@umcutrecht.nl)
}

\begin{abstract}
Objective: To investigate whether circulating levels of testosterone (total, bioavailable), estradiol (total, bioavailable), and DHEA sulfate (DHEAS) are associated with fasting plasma homocysteine (tHcy) levels in middle-aged and elderly men.

Design: A population-based sample of 400 independently living men between 40 and 80 years of age in a cross-sectional study.

Methods: Total testosterone, sex hormone binding globulin (SHBG), and total estradiol were measured by RIA methods and bioavailable testosterone and estradiol were calculated. DHEAS was measured using an immunometric technique. Fasting homocysteine was measured by fluorescence polarization immunoassay. Anthropometric characteristics were also measured and two standardized questionnaires completed, including life-style factors and diet. Linear regression analysis adjusted for age, body mass index (BMI), creatinine clearance, and mean visceral fat was used to assess the association of endogenous sex hormones and fasting plasma homocysteine levels.

Results: After adjustment for age, BMI, creatinine clearance, and mean visceral fat no statistically significant association was observed between testosterone (total, bioavailable), DHEAS, and estradiol (total, bioavailable)levels with natural $\log$ tHcy $\left(\beta=-2 \times 10^{-3} ; 95 \%\right.$ confidence intervals (CI) $-9 \times$ $\left.10^{-3} ; 5 \times 10^{-3}\right),\left(\beta=-4 \times 10^{-3} ; 95 \%\right.$ CI $\left.-18 \times 10^{-3} ; 9 \times 10^{-3}\right),\left(\beta=3 \times 10^{-3} ; 95 \% \mathrm{CI}-6 \times 10^{-3}\right.$; $\left.12 \times 10^{-3}\right),\left(\beta=-9.3 \times 10^{-5} ; 95 \% \mathrm{CI}-1 \times 10^{-3} ; 1 \times 10^{-3}\right)$, and $\left(\beta=0.00 ; 95 \% \mathrm{CI}-3 \times 10^{-3} ; 2 \times\right.$ $10^{-3}$ ) respectively. Additional adjustment for smoking, alcohol intake, daily physical activity, diabetes mellitus, and hypertension did not change these findings.

Conclusion: The results of our study do not support a direct role for circulating sex hormone levels in the regulation of fasting plasma tHcy concentrations in middle-aged and elderly men.
\end{abstract}

European Journal of Endocrinology 155 887-893

\section{Introduction}

Endogenous androgens are increasingly being investigated in relation to cardiovascular risk factors and as potential predictors of health problems affecting men (1). Testosterone and estradiol levels (total, free, and non-sex hormone binding globulin (SHBG)-bound) decline significantly with ageing, whereas SHBG levels increase, making the effective decrease in free and bioavailable testosterone and estradiol even more pronounced (2). Other important androgenic hormones demonstrating age-related declines are the circulating levels of DHEA and its sulfate (DHEA-S) $(3,4)$.

Many studies have demonstrated that the lower androgen levels are associated with an increased risk of cardiovascular disease (CVD) $(5,6)$. Others however found no relationship (7-10).

Increased levels of plasma total homocysteine (tHcy) are also common in elderly people $(11,12)$. Plasma
tHcy has shown to be a strong and independent risk factor for CVD (13, 14), although the etiological meaning of this finding is less clear, since recent studies indicate that lowering tHcy levels does not decrease CVD risk $(15,16)$.

A few prior studies have reported data on the probable association of various endogenous sex hormones and homocysteine levels. It has been shown that men have higher tHcy concentrations than women, typically about 10-15\% higher levels but this difference is attenuated after menopause (17). One study found that tHcy levels are typically lower during pregnancy, a state characterized by high levels of endogenous estrogens (18). Moreover, plasma tHcy concentrations were high in patients with polycystic ovary syndrome, a condition characterized by androgen excess (19). In addition, a study in transsexual males and females showed that tHcy levels decrease after estrogens and anti-androgen administration to male (transsexual) 
subjects (20). Androgen supplementation has been found to induce hyperhomocysteinemia in men taking anabolic androgenic steroids, and also in men with Klinefelter's syndrome when given supraphysiologic doses of testosterone $(21,22)$. These evidences could be mediated by possible association between endogenous sex hormone and tHcy levels. The aim of present study was to determine the relation of endogenous testosterone (total, bioavailable), total estradiol, DHEA-S levels, and fasting plasma tHcy levels in middle-aged and elderly men.

\section{Subjects and methods}

We conducted a cross-sectional study in 400 men aged 40-80 years apparently healthy at the time of enrollment. Details of the study design, recruitment, and procedures have been published $(23,24)$. The study was approved by the institutional Review Board of the University Medical Center Utrecht and written informed consent was obtained from all participants.

\section{Homocysteine measurement}

Fasting plasma concentration of tHcy was determined as free plus protein-bound tHcy by Fluorescence Polarization Immunoassay on an IMx Analyzer (Abbott Diagnostics, Hoofddorp, The Netherlands). For variation reduction in plasma tHcy measurement, sampling was done in standardized sitting down position. The samples were coagulated with EDTA and centrifuged after collection (25). The inter-assay variation is $3.9 ; 4.2$ and $3.9 \%$ at $9.9 ; 18.1$ and $41.0 \mu \mathrm{mol} / \mathrm{l}$ respectively $(n=$ 73 ) and the lower limit of detection was $0.5 \mu \mathrm{mol} / \mathrm{l}$.

\section{Sex hormone measurements}

A venapuncture was performed between 0800 and $1000 \mathrm{~h}$ after overnight fasting and a blood sample was obtained. Platelet-free serum and plasma was obtained by centrifugation and immediately stored at $-20{ }^{\circ} \mathrm{C}$. Circulating androgens levels were measured in serum. Total testosterone (TT) was measured after diethyl ether extraction using an in-house competitive RIA employing a polyclonal anti-testosterone-antibody (Dr Pratt AZG 3290). The lower limit of detection was $0.24 \mathrm{nmol} / \mathrm{l}$ and the inter-assay variation was $6.0 ; 5.4$ and $8.6 \%$ at 2.1 ; 5.6 and $23 \mathrm{nmol} / \mathrm{l}$ respectively $(n=85)$. Bioavailable testosterone (free plus albumin bound) was calculated from measures of TT and immunoassayed SHBG concentrations and albumin using the method described by Vermeulen et al. (26). Estradiol was measured after diethyl ether extraction and Sephadex chromatography using an in-house competitive RIA employing a polyclonal anti-estradiol-antibody (Dr F de Jong, Erasmus MC, Rotterdam, The Netherlands). The lower limit of detection was $20 \mathrm{pmol} / \mathrm{l}$ and the inter-assay variation was $10.0 \%$ at $81 \mathrm{pmol} / \mathrm{l}$ and $3.1 \%$ at $660 \mathrm{pmol} / \mathrm{l}(n=24$, resp. 17). Bioavailable estradiol was calculated using the method described by Södergard et al. (27). This method is based on the knowledge of the total concentration of all steroids competing for the same binding site on SHBG, the concentration of albumin (using a fixed concentration of $40 \mathrm{~g} / \mathrm{l}$ ), the binding capacity of SHBG, and the association constant of estradiol to the binding proteins. DHEA-S was measured using an immunometric technique on an advantage chemiluminescence system (Nichols Institute Diagnostics, San Juan Capistrano, CA, USA). The lower limit of detection was $0.1 \mu \mathrm{mol} / \mathrm{l}$ and the inter-assay variation was $5.2 ; 5.6$ and $4.2 \%$ at $1.0 ; 4.9$ and $14.2 \mu \mathrm{mol} / \mathrm{l}$ respectively $(n=19)$. SHBG was measured using an immunometric technique on an IMMULITE Analyser (Diagnostic Products Corporation, Los Angeles, CA, USA). The lower limit of detection was $5 \mathrm{nmol} / \mathrm{l}$ and the inter-assay variation was $6.1 \%$ at $11.6 \mathrm{nmol} / \mathrm{l}, 4.9 \%$ at $36 \mathrm{nmol} / \mathrm{l}$, and $6.9 \%$ at $93 \mathrm{nmol} / \mathrm{l}$ $(n=30)$.

\section{Other measurements}

A trained physician obtained information on prevalent diseases, medication use, and life-style factors. Smoking was estimated from self-report and categorized in present, former, and never smokers. Alcohol consumption was assessed by a validated Food Frequency Questionnaire designed to estimate regular intake of 178 food items in the year prior to enrolment (28). Height and weight were measured in standing position without shoes. Waist and hip circumference were measured using a standard household tapemeasure and rounded to the nearest centimeter. Waist-to-hip ratio was calculated by dividing waist circumference by hip circumference. Blood pressure (BP) was measured twice at the right brachial artery with a semiautomated device (Dinamap, GE HealthCare, Tampa, FL, USA). The average of the two measurements of systolic and diastolic BP was used for analysis and further calculation. Body mass index (BMI) was calculated as the weight in kilograms divided by the square of the height in meters $\left(\mathrm{kg} / \mathrm{m}^{2}\right)$. Visceral and s.c. fat were measured using ultrasound measurement (29). Ultrasonography was performed with an HDI 3000 (Philips Medical Systems, Eindhoven, The Netherlands) using a C 4-2 transducer. For all images, the transducer was placed on a straight line drawn between the left and the right midpoints between the lower rib and the iliac crest. Measurements were made at the end of quiet expiration applying minimal pressure without displacement of intra-abdominal contents as observed by ultrasound image. Visceral fat comprises the distance between peritoneum and lumbar spine. s.c. fat comprises the distance between the skin and the linea alba. For the measurement of visceral fat mass, we measured distances from three different angles (medial, left, and right). For the s.c. fat mass, the distance from 
the medial angle was measured in threefold. The mean of the three different measurements was calculated and used in our analyses (30). Physical activity was assessed using a questionnaire validated in an elderly population and was categorized in quartiles (31).

Fasting glucose levels were assessed using a GlucoTouch reflectometer (LifeScan, Inc., Benelux, Beese, Belgium), a reagent-strip glucose oxidase methods. Serum creatinine was measured by the Jaffe rate method (The SYNCHRON LXi 725, Beckman Coulter, Fullerton, CA, USA). Creatinine clearance was calculated from serum creatinine, age, and body weight according to the Cockcroft-Gault formula (140-age (year) $\times$ weight $(\mathrm{kg}) \times$ constant/serum creatinine $(\mu \mathrm{mol} / \mathrm{l}))(32)$. An automatic enzymatic procedure was used to determine serum total cholesterol (Synchron LX Systems; Beckman Coulter). High-density lipoprotein cholesterol and triglycerides were measured similarly.

Diabetes mellitus was defined as treatment with insulin or oral hypoglycemic agents or fasting plasma venous glucose $>6.9 \mathrm{mmol} / \mathrm{l}$. Hypertension was defined as systolic BP $\geq 160 \mathrm{mmHg}$ and/or diastolic $\mathrm{BP} \geq 95 \mathrm{mmHg}$ and/or use of anti-hypertensive medication. Hyperlipidemia was defined as serum total cholesterol $>6.5 \mathrm{mmol} / \mathrm{l}$ and/or treatment with lipidlowering medication. The subject's customary alcohol intake, caffeine use, daily intake of vitamin B groups, protein, methionine, and folate were estimated from a validated food frequency questionnaire. Presence of CVD was defined as coronary heart disease, peripheral artery disease, or stroke.

\section{Data analysis}

The data were analyzed using the SPSS statistical package for windows version 11.0 (SPSS Inc., Chicago, IL, USA). We excluded the subjects with cardiovascular disease (CVD) $(n=58)$ because it has been shown that patients with prevalent CVD have higher homocysteine levels and lower sex hormone levels than patients without. Therefore, inclusion of subjects with prevalent disease may lead to spurious correlation. We examined the normality assumptions for the variables with the Kolmogorov-Smirnov test. Since the tHcy and triglyceride concentrations were skewed, we used log-transformed values. For alcohol consumption as data suggested the presence of a J-shaped relation, therefore alcohol intake was divided into four levels $(0-3,4-$ $10,11-21$ and 22-higher unit per week) and the first group was chosen as the reference group in the analysis. The alcohol intake levels and smoking were put into the model as dummy variables. The association between circulating serum sex hormone levels and natural log plasma tHcy was examined using linear regression coefficients $(\beta)$ and corresponding 95\% confidence intervals (CI). To determine whether and to what extent the observed associations of sex hormone levels with might be explained by intermediate factors, multivariate regression analysis were used with adjustment for age, BMI, creatinine clearance, and mean visceral fat, as based on literature indicating there to be major determinants of circulating sex hormones and plasma tHcy (model A). Further adjustment has been done for smoking, alcohol intake and daily physical activity (model B), and hypertension and diabetes mellitus (model C) respectively. Because of the large effect of age and obesity (waist-to-hip ratio $\geq 0.98$ ) on plasma tHcy and sex hormone levels, effect modification was tested by adding the interaction terms to the multivariate model. Stratified analyses were presented when the interaction term was statistically significant $(P$ value $<0.05)$.

\section{Results}

The mean age of the population was 60 years and the median of fasting tHcy was $12.10 \mu \mathrm{mol} / \mathrm{l}(9.40-17.50)$ (Table 1). Mild $(15-16 \mu \mathrm{mol} / \mathrm{l})$ and intermediate (16-30 $\mathrm{mol} / \mathrm{l})$ hyperhomocysteinemia were shown by 21.3 and $0.8 \%$ of subjects respectively. Subjects

Table 1 Characteristics of the study population $(n=342)$.

\begin{tabular}{|c|c|}
\hline Characteristic & Mean \pm s.D. \\
\hline Age (years) & $60.2 \pm 11.3$ \\
\hline Height $(\mathrm{cm})$ & $177.94 \pm 7.2$ \\
\hline Weight (kg) & $83.22 \pm 12.20$ \\
\hline BMI $\left(\mathrm{kg} / \mathrm{m}^{2}\right)$ & $26.27 \pm 3.47$ \\
\hline Waist-to-hip ratio & $0.97 \pm 0.06$ \\
\hline Systolic blood pressure $(\mathrm{mmHg})$ & $143.4 \pm 22.1$ \\
\hline Diastolic blood pressure $(\mathrm{mmHg})$ & $81.5 \pm 10.3$ \\
\hline Visceral fat $(\mathrm{cm})$ & $7.54 \pm 2.23$ \\
\hline s.c. fat $(\mathrm{cm})$ & $2.64 \pm 0.85$ \\
\hline Visceral and s.c. fat $(\mathrm{cm})$ & $10.09 \pm 2.45$ \\
\hline Serum creatinine $(\mu \mathrm{mol} / \mathrm{l})$ & $90.0 \pm 14.2$ \\
\hline Creatinine clearance $(\mathrm{ml} / \mathrm{min})$ & $1.07 \pm 0.29$ \\
\hline Total cholesterol (mmol/l) & $5.89 \pm 1.03$ \\
\hline Glucose $(\mathrm{mmol} / \mathrm{l})$ & $5.96 \pm 1.45$ \\
\hline Physical activity (Voorrips score) & $18.06 \pm 7.46$ \\
\hline \multicolumn{2}{|l|}{ Hormone levels } \\
\hline Total testosterone $(\mathrm{nmol} / \mathrm{l})$ & $18.53 \pm 5.33$ \\
\hline Bioavailable testosterone $(\mathrm{nmol} / \mathrm{l})$ & $8.14 \pm 2.25$ \\
\hline Total estradiol (pmol/l) & $91.25 \pm 22.84$ \\
\hline Bioavailable estradiol (pmol//) & $42.19 \pm 11.44$ \\
\hline SHBG (nmol/l) & $40.58 \pm 14.46$ \\
\hline DHEAS $(\mu \mathrm{mol} / \mathrm{l})$ & $6.67 \pm 3.28$ \\
\hline \multirow[t]{2}{*}{ Homocysteine $(\mu \mathrm{mol} / \mathrm{l})$} & $13.20 \pm 4.01$ \\
\hline & Median (percentiles 10-90) \\
\hline Triglyceride $(\mathrm{mmol} / \mathrm{l})$ & $1.20(0.70-2.72)$ \\
\hline Alcohol use (units/week) & $10(0.0-31.8)$ \\
\hline Daily caffeine use (mg) & $399.2(166.6-641.7)$ \\
\hline \multirow[t]{2}{*}{ Homocysteine $(\mu \mathrm{mol} / \mathrm{l})$} & $12.10(9.40-17.50)$ \\
\hline & $n(\%)$ \\
\hline Hypertension & $79(23.0)$ \\
\hline Diabetes mellitus & 77 (23.0) \\
\hline \multicolumn{2}{|l|}{ Alcohol use (units/week) } \\
\hline $0-3$ & $86(25.5)$ \\
\hline $4-10$ & 87 (26.0) \\
\hline $11-21$ & $93(28.0)$ \\
\hline $22 \leq$ & $69(20.5)$ \\
\hline Present smoking & $79(23)$ \\
\hline
\end{tabular}


with the highest bioavailable testosterone level were younger, less likely to have CVD, hypertension and diabetes mellitus, and more likely to be a present smoker. General characteristics of study subjects across the quartiles of bioavailable testosterone levels are shown in Table 2.

In the unadjusted model, natural log homocysteine decreased significantly with increasing testosterone (total, bioavailable) levels; natural log homocysteine was $8 \times 10^{-3}\left(95 \% \mathrm{CI}-14 \times 10^{-3} ; 2 \times 10^{-3}\right) \mu \mathrm{mol} / \mathrm{l}$ and $17 \times 10^{-3}\left(95 \%\right.$ CI $\left.-28 \times 10^{-3} ;-5 \times 10^{-3}\right)$ $\mu \mathrm{mol} / \mathrm{l}$ lower for each one $\mathrm{nmol} / \mathrm{l}$ increase in testosterone (total, bioavailable) levels respectively. Multiple regression analysis adjusted for age, BMI, creatinine clearance, and mean visceral fat showed no statistically significant association between testosterone (total, bioavailable), DHEAS, and estradiol (total, bioavailable) levels with natural $\log$ tHcy $\left(\beta=-2 \times 10^{-3} ; 95 \%\right.$ CI $\left.-9 \times 10^{-3} ; 5 \times 10^{-3}\right), \quad\left(\beta=-4 \times 10^{-3} ; 95 \%\right.$ CI $\left.-18 \times 10^{-3} ; 9 \times 10^{-3}\right),\left(\beta=3 \times 10^{-3} ; 95 \% \mathrm{CI}-6 \times\right.$ $\left.10^{-3} ; 12 \times 10^{-3}\right),\left(\beta=-9.3 \times 10^{-3} ; 95 \% \mathrm{CI}-1 \times\right.$ $\left.10^{-3} ; 1 \times 10^{-3}\right)$, and $\left(\beta=0.00 ; 95 \% \mathrm{CI}-3 \times 10^{-3}\right.$; $2 \times 10^{-3}$ ) respectively (Table 3). Further adjustment for smoking, alcohol intake, and daily physical activity diabetes mellitus, hypertension did not materially alter the results $\left(\beta=-2 \times 10^{-3} ; 95 \% \mathrm{CI}-10 \times 10^{-3} ; 5 \times\right.$ $\left.10^{-3}\right),\left(\beta=-4 \times 10^{-3} ; 95 \%\right.$ CI $-19 \times 10^{-3} ; 10 \times$ $\left.10^{-3}\right),\left(\beta=2 \times 10^{-3} ; 95 \% \mathrm{CI}-8 \times 10^{-3} ; 12 \times 10^{-3}\right)$, $\left(\beta=0.00 ; \quad 95 \% \quad\right.$ CI $\left.-1 \times 10^{-3} ; 1 \times 10^{-3}\right)$, and $\left(\beta=0.00 ; 95 \% \mathrm{CI}-3 \times 10^{-3} ; 2 \times 10^{-3}\right)$ respectively.

\section{Discussion}

In this population-based study, we found no support that circulating testosterone (total, bioavailable), estradiol, or DHEA sulfate levels and fasting plasma tHcy are independently related in middle-aged and elderly men.

Our result in this study is in some part in agreement with results of previously conducted studies, which showed no association between fasting plasma tHcy and androgen supplementation in healthy men. In a crossover study which has been conducted to assess the effects of supraphysiologic does of testosterone, with or without aromatization to estradiol in eugonadal men, it has been shown that fasting tHcy levels were not significantly altered during either testosterone condition, suggesting that testosterone and its aromatization to estradiol does not affect tHcy concentrations (33). A case-control study of patients with idiopathic hypogonadotropic hypogonadism treated with gonadotropin and controls showed that plasma tHcy concentrations were independent of changes in androgen levels (34). Similar to present finding in a prospective clinical study, it has been shown that supraphysiologic doses of testosterone increased plasma tHcy levels in men with

Table 2 Characteristics of the study population according to different quartiles of bioavailable testosterone levels.

\begin{tabular}{|c|c|c|c|c|c|}
\hline & $\begin{array}{c}\text { Quartile1 } \\
(n=79)\end{array}$ & $\begin{array}{c}\text { Quartile2 } \\
(n=84)\end{array}$ & $\begin{array}{c}\text { Quartile3 } \\
(n=88)\end{array}$ & $\begin{array}{c}\text { Quartile4 } \\
(n=91)\end{array}$ & $P$ value \\
\hline \multicolumn{6}{|l|}{ Mean士s.D. } \\
\hline Bioavailable testosterone $(\mathrm{nmol} / \mathrm{l})$ & $5.56 \pm 0.97$ & $7.27 \pm 0.29$ & $8.54 \pm 0.44$ & $11.20 \pm 1.46$ & 0.00 \\
\hline Age (years) & $66.58 \pm 8.79$ & $63.31 \pm 10.45$ & $59.79 \pm 10.81$ & $51.22 \pm 8.86$ & 0.00 \\
\hline SHBG $(\mathrm{nmol} / \mathrm{l})$ & $30.21 \pm 10.04$ & $37.29 \pm 10.77$ & $42.79 \pm 11.76$ & $52.06 \pm 15.44$ & 0.08 \\
\hline Systolic blood pressure (mmHg) & $150.32 \pm 25.05$ & $143.85 \pm 22.97$ & $142.41 \pm 19.96$ & $137.03 \pm 18.00$ & 0.00 \\
\hline Diastolic blood pressure $(\mathrm{mmHg})$ & $83.28+9.40$ & $81.04+10.86$ & $81.29+11.02$ & $80.34+9.64$ & 0.13 \\
\hline Total folate intake $(\mu \mathrm{g})$ & $222.67 \pm 75.13$ & $219.87 \pm 57.50$ & $211.97 \pm 53.35$ & $210.94 \pm 53.99$ & 0.43 \\
\hline $\mathrm{BMI}\left(\mathrm{kg} / \mathrm{m}^{2}\right)$ & $26.09+2.93$ & $26.45+3.45$ & $25.98+3.99$ & $26.56+3.45$ & 0.54 \\
\hline Waist-to-hip ratio & $0.99 \pm 0.06$ & $0.98 \pm 0.05$ & $0.98 \pm 0.05$ & $0.94 \pm 0.06$ & 0.00 \\
\hline Visceral fat $(\mathrm{cm})$ & $8.06 \pm 2.62$ & $7.86 \pm 1.86$ & $7.43 \pm 2.19$ & $6.73 \pm 1.93$ & 0.00 \\
\hline S.c. fat $(\mathrm{cm})$ & $2.82 \pm 0.98$ & $2.62 \pm 0.67$ & $2.67 \pm 0.81$ & $2.48 \pm 0.91$ & 0.05 \\
\hline Visceral and s.c. fat $(\mathrm{cm})$ & $10.78 \pm 2.98$ & $10.35 \pm 1.95$ & $10.01 \pm 2.34$ & $9.20 \pm 2.18$ & 0.00 \\
\hline Serum creatinine $(\mu \mathrm{mol} / \mathrm{l})$ & $91.1+15.8$ & $92.32+17.9$ & $91.60+17.1$ & $89.7+12.4$ & 0.70 \\
\hline Creatinine clearance $(\mathrm{ml} / \mathrm{min})$ & $0.99 \pm 0.30$ & $1.05 \pm 0.30$ & $1.06 \pm 0.31$ & $1.15 \pm 0.21$ & 0.00 \\
\hline Total cholesterol $(\mathrm{mmol} / \mathrm{l})$ & $5.52 \pm 1.06$ & $5.82 \pm 0.95$ & $5.59 \pm 1.04$ & $5.90 \pm 1.09$ & 0.01 \\
\hline Physical activity (Voorrips score) & $18.4 \pm 7.2$ & $17.4 \pm 8.4$ & $18.3 \pm 7.0$ & $18.1 \pm 7.2$ & 0.36 \\
\hline $\begin{array}{l}\text { Median (percentIles 10-90) } \\
\text { Triglyceride }(\mathrm{mmol} / \mathrm{l})\end{array}$ & $1.20(0.79-2.53)$ & $1.30(0.74-3.38)$ & $1.20(0.60-2.83)$ & $1.20(0.70-2.29)$ & \\
\hline Alcohol use (unit/week) & $9.0(0.0-34.0)$ & $8.0(0.0-34.7)$ & $10.0(0.8-34.8)$ & $11.0(0.0-30.10)$ & \\
\hline Daily caffeine use (mg) & $422(110-631)$ & $433(225-659)$ & $395(157-647)$ & $357(158-712)$ & \\
\hline $\begin{array}{l}\text { Homocysteine }(\mu \mathrm{mol} / \mathrm{l}) \\
N(\%)\end{array}$ & $12.45(9.49-18.97)$ & $11.60(9.26-17.62)$ & $12.40(9.32-18.06)$ & $11.85(8.91-15.49)$ & \\
\hline Hypertension & $28(36)$ & $25(30)$ & $18(21)$ & $6(6.7)$ & 0.00 \\
\hline Diabetes mellitus & $12(15)$ & $10(12)$ & $8(9.2)$ & $3(3.3)$ & 0.05 \\
\hline \multicolumn{6}{|l|}{ Alcohol use (unit/week) } \\
\hline $0-3$ & $26(33.3)$ & $20(24.1)$ & $14(16.1)$ & $26(28.9)$ & 0.07 \\
\hline $4-10$ & $15(19.2)$ & $24(28.9)$ & $31(35.6)$ & $17(18.9)$ & 0.03 \\
\hline $11-21$ & 25 (32.1) & $17(20.5)$ & $27(31.0)$ & $24(26.7)$ & 0.33 \\
\hline $22 \leq$ & $12(15.4)$ & $21(25.3)$ & $15(17.2)$ & $21(23.3)$ & 0.33 \\
\hline Present smoking & $15(19)$ & $18(22)$ & $16(18)$ & $30(33)$ & 0.07 \\
\hline
\end{tabular}


Table 3 Regression coefficients from linear regression models including natural log homocysteine level as the dependent variable and endogenous sex hormone levels as the independent variable.

\begin{tabular}{|c|c|c|}
\hline & $\begin{array}{c}\text { Regression } \\
\text { coefficient } \\
(\mu \mathrm{mol} / \mathrm{l})\end{array}$ & $95 \% \mathrm{Cl}$ \\
\hline \multicolumn{3}{|c|}{ Total testosterone $(\mathrm{nmol} / \mathrm{l})^{\mathrm{a}}$} \\
\hline Crude & $-8 \times 10^{-3}$ & $\left(-14 \times 10^{-3} ;-2 \times 10^{-3}\right)$ \\
\hline Model $A^{b}$ & $-2 \times 10^{-3}$ & $\left(-9 \times 10^{-3} ; 5 \times 10^{-3}\right)$ \\
\hline Model Bc & $-2 \times 10^{-3}$ & $\left(-10 \times 10^{-3} ; 5 \times 10^{-3}\right)$ \\
\hline Model $C^{d}$ & $-2 \times 10^{-3}$ & $\left(-10 \times 10^{-3} ; 5 \times 10^{-3}\right)$ \\
\hline \multicolumn{3}{|c|}{ Bioavailable testosterone $(\mathrm{nmol} / \mathrm{l})$} \\
\hline Crude & $-17 \times 10^{-3}$ & $\left(-28 \times 10^{-3} ;-5 \times 10^{-3}\right)$ \\
\hline Model A & $-4 \times 10^{-3}$ & $\left(-18 \times 10^{-3} ; 9 \times 10^{-3}\right)$ \\
\hline Model B & $-5 \times 10^{-3}$ & $\left(-19 \times 10^{-3} ; 9 \times 10^{-3}\right)$ \\
\hline Model C & $-4 \times 10^{-3}$ & $\left(-19 \times 10^{-3} ; 10 \times 10^{-3}\right)$ \\
\hline \multicolumn{3}{|c|}{ DHEAS $(\mu \mathrm{mol} / \mathrm{l})$} \\
\hline Crude & $-10 \times 10^{-3}$ & $\left(-18 \times 10^{-3} ;-1 \times 10^{-3}\right)$ \\
\hline Model A & $3 \times 10^{-3}$ & $\left(-6 \times 10^{-3} ; 12 \times 10^{-3}\right)$ \\
\hline Model B & $3 \times 10^{-3}$ & $\left(-7 \times 10^{-3} ; 12 \times 10^{-3}\right)$ \\
\hline Model C & $2 \times 10^{-3}$ & $\left(-8 \times 10^{-3} ; 12 \times 10^{-3}\right)$ \\
\hline \multicolumn{3}{|c|}{ Total E2 $(\mathrm{pmol} / \mathrm{l})^{\mathrm{a}}$} \\
\hline Crude & 0.00 & $\left(-1 \times 10^{-3} ; 1 \times 10^{-3}\right)$ \\
\hline Model A & $-9.3 \times 10^{-5}$ & $\left(-1 \times 10^{-3} ; 1 \times 10^{-3}\right)$ \\
\hline Model B & 0.00 & $\left(-1 \times 10^{-3} ; 1 \times 10^{-3}\right)$ \\
\hline Model C & 0.00 & $\left(-1 \times 10^{-3} ; 1 \times 10^{-3}\right)$ \\
\hline \multicolumn{3}{|c|}{ Bioavailable E2 (pmol/l) } \\
\hline Crude & $-1 \times 10^{-3}$ & $\left(-4 \times 10^{-3} ; 1 \times 10^{-3}\right)$ \\
\hline Model A & 0.00 & $\left(-3 \times 10^{-3} ; 2 \times 10^{-3}\right)$ \\
\hline Model B & 0.00 & $\left(-3 \times 10^{-3} ; 2 \times 10^{-3}\right)$ \\
\hline Model C & 0.00 & $\left(-3 \times 10^{-3} ; 2 \times 10^{-3}\right)$ \\
\hline
\end{tabular}

E2, estradiol; $\mathrm{Cl}$, Confidence interval

${ }^{a}$ Additional adjustment for Sex hormone-binding globulin.

${ }^{\mathrm{b}}$ Adjusted for age, body mass index (BMI), creatinine clearance, and mean visceral fat.

${ }^{c}$ Adjusted for age, BMI, creatinine clearance, mean visceral fat, smoking, alcohol intake, and physical activity.

${ }^{\mathrm{d}}$ Adjusted for age, BMI, creatinine clearance, mean visceral fat, smoking, alcohol intake, physical activity, diabetes mellitus, and hypertension.

Klinefelter's syndrome potentially through changes in creatinine, cobalamin, and folate (22). However, in a study performed in transsexual male and female subjects, plasma thcy levels increased after androgen administration to female (transsexual) subjects and substantially decreased in male (transsexual) subjects after estrogen and anti-androgen administration respectively (20). Similarly, in young bodybuilders, the intake of anabolic androgenic steroid induced acute hyperhomocysteinemia (21).

The best explanation for the observed gender difference in plasma tHcy concentration is the relation of tHcy concentrations with lean body mass, protein turnover, and creatinine production, all of which tend to be higher in men than women (35). The relation between circulating concentrations of tHcy and serum creatinine, as one of the most important determinants of fasting homocysteine, may largely reflect the effect of renal function on homocysteine concentrations, but tHcy and creatinine could be also be related because of increased homocysteine production during creatinine metabolism. In female to male transsexuals, in addition to plasma creatinine levels, the creatinine excretion rate, lean body mass, and BMI increased. Therefore, sex steroid-induced change in plasma tHcy levels could conceivably be explained by their anabolic/ catabolic effects.

Exogenous estrogen in elderly men has been suggested to reduce plasma tHcy levels (36). Previous studies have suggested a protective role for endogenous estrogens in cardiovascular system in men (37). Furthermore, estradiol supplementation has been shown to improve endothelial function in both elderly hypogonadal and healthy men receiving testosterone $(38,39)$. It has been suggested that the suppression of endogenous estrogens with an aromatase inhibitor resulted in a decrease in the estradiol level and an impairment of endothelial function, determined by flow-mediated dilatation of the brachial artery, without significant changes in lipoproteins or homocysteine (40). It has been suggested that the estradiol prevents Hcy-induced endothelial damage in male rats (41). The most important beneficial effects of estradiol on CVD are opposite of those harmful effects induced by Hcy. Furthermore, it has been found in this study that the beneficial effects of estradiol on endothelium were related closely to lower serum tHcy concentrations.

DHEAS is an abundant steroid hormone that is a precursor for both estrogens and testosterone with unknown biological functions. Several clinical and population-based studies suggest that DHEAS plays a protective role against atherosclerosis and coronary artery disease in men $(42,43)$. One study found that chronic DHEA supplementation exerts anti-atherogenic effects although homocysteine concentrations were not modified by the treatment (44). It seems likely that the anti-atherogenic effects of DHEAS are independent of its action on plasma homocysteine concentrations.

The present study has some limitations. Homocysteine is metabolized by remethylation to methionine or by transsulfuration to cysteine. The remethylation pathway regulates fasting levels of homocysteine, whereas the methionine load test measures the activity of the tHcy catabolic transsulfuration pathway. It has been shown that fasting tHcy levels are only weakly related to the tHcy response to methionine loading (45); therefore, we cannot exclude the possibility that endogenous androgens influence the tHcy catabolic transsulfuration pathway. In addition, the interpretability of the results may be restricted by several factors inherent to the cross-sectional design and do not provide direct evidence of cause and effect. Another limitation is that because of within-subject biological variation, the single measurement of both sex hormones and several risk factors will reflect long-term averages less precisely than repeated measurements.

In summary, we found no significant association of testosterone (total, bioavailable), estradiol (total, bioavailable), or DHEAS levels with fasting plasma homocysteine levels in middle-aged and elderly men. 


\section{References}

1 Morley JE, Kaiser FE, Sih R, Hajjar R \& Perry HM, III. Testosterone and frailty. Clinics in Geriatric Medicine 199713 685-695.

2 Feldman HA, Longcope C, Derby CA, Johannes CB, Araujo AB, Coviello AD, Bremner WJ \& Mckinlay JB. Age trends in the level of serum testosterone and other hormones in middle-aged men: longitudinal results from the Massachusetts male aging study. Journal of Clinical Endocrinology and Metabolism 2002 87 589-598.

3 Hinson J \& Raven P. DHEA deficiency syndrome: a new term for old age? Journal of Endocrinology 1999163 1-5.

4 Simpson ER \& Davis SR. Minireview: aromatase and the regulation of estrogen biosynthesis-some new perspectives. Endocrinology $20011424589-4594$.

5 Alexandersen P, Haarbo J \& Christiansen C. The relationship of natural androgens to coronary heart disease in males: a review. Atherosclerosis $1996 \mathbf{1 2 5} 1-13$.

6 Muller M, Van Den Beld AW, Bots ML, Grobbee DE, Lamberts SWJ \& Van der Schouw YT. Endogenous sex hormones and progression of carotid atherosclerosis in elderly men. Circulation 2004109 2074-2079.

7 Barrett-Connor E \& Khaw KT. Endogenous sex hormones and cardiovascular disease in men. A prospective population-based study. Circulation 1988 78 539-545.

8 Cauley JA, Gutai JP, Kuller LH \& Dai WS. Usefulness of sex steroid hormone levels in predicting coronary artery disease in men. American Journal of Cardiology 198760 771-777.

9 Phillips GB, Yano K \& Stemmermann GN. Serum sex hormone levels and myocardial infarction in the Honolulu Heart Program. Pitfalls in prospective studies on sex hormones. Journal of Clinical Epidemiology $1988 \mathbf{4 1} 1151-1156$.

10 Yarnell JW, Beswick AD, Sweetnam PM \& Riad-Fahmy D. Endogenous sex hormones and ischemic heart disease in men. The Caerphilly Prospective Study. Arteriosclerosis and Thrombosis $199313517-520$.

11 Joosten E, Van Den Berg A, Riezler R, Naurath $H$, Lindenbaum J, Stabler S \& Allen R. Metabolic evidence that deficiencies of vitamin B-12 (cobalamin), folate, and vitamin B-6 occur commonly in elderly people. American Journal of Clinical Nutrition $1993 \mathbf{5 8} 468-476$.

12 Selhub J, Jacques PF, Wilson PW, Rush D \& Rosenberg IH. Vitamin status and intake as primary determinants of homocysteinemia in an elderly population. Journal of the American Medical Association $19932702693-2698$.

13 Nygard O, Vollset SE, Refsum H, Brattstrom L \& Ueland PM. Total homocysteine and cardiovascular disease. Journal of Internal Medicine 1999246 425-454.

14 Eikelboom JW, Lonn E, Genest J, Jr, Hankey G \& Yusuf S. Homocyst(e)ine and cardiovascular disease: a critical review of the epidemiologic evidence. Annals of Internal Medicine 1999131 363-375.

15 Bonaa KH, Njolstad I, Ueland PM, Schirmer H, Tverdal A, Steigen T, Wang H, Nordrehaug JE, Arnesen E, Rasmussen K \& The NTI, . Homocysteine lowering and cardiovascular events after acute myocardial infarction. New England Journal of Medicine 2006 354 1578-1588.

16 The Heart Outcomes Prevention Evaluation I. Homocysteine lowering with folic acid and B vitamins in vascular disease. New England Journal of Medicine 2006354 1567-1577.

17 Fonseca V, Guba SC \& Fink LM. Hyperhomocysteinemia and the endocrine system: implications for atherosclerosis and thrombosis. Endocrine Reviews 199920 738-759.

18 Andersson A, Hultberg B \& Brattstrom L. Decreased serum homocysteine in pregnancy. European Journal of Clinical Chemistry and Clinical Biochemistry 199230 377-379.

19 Yarali H, Yildirir A, Aybar F, Kabakci G, Bukulmez O, Akgul E \& Oto A. Diastolic dysfunction and increased serum homocysteine concentrations may contribute to increased cardiovascular risk in patients with polycystic ovary syndrome. Fertility and Sterility $200176511-516$.
20 Giltay EJ, Hoogeveen EK, Elbers JMH, Gooren LJG, Asscheman H \& Stehouwer CDA. Effects of sex steroids on plasma total homocysteine levels: a study in transsexual males and females. Journal of Clinical Endocrinology and Metabolism 199883 550-553.

21 Ebenbichler CF, Kaser S, Bodner J, Gander R, Lechleitner M, Herold M \& Patsch JR. Hyperhomocysteinemia in bodybuilders taking anabolic steroids. European Journal of Internal Medicine 2001 12 43-47.

22 Yesilova Z, Ozata M, Oktenli C, Sanisoglu SY, Erbil MK \& Dagalp K. Effect of supraphysiologic doses of testosterone on fasting plasma total homocysteine concentrations in men with Klinefelter's syndrome. Fertility and Sterility 200481 1278-1282.

23 Muller M, Aleman A, Grobbee DE, De Haan EHF \& Van Der Schouw YT. Endogenous sex hormone levels and cognitive function in aging men: is there an optimal level? Neurology $200564866-871$.

24 Aleman A, Muller M, De Haan EHF \& Van Der Schouw YT. Vascular risk factors and cognitive function in a sample of independently living men. Neurobiology of Aging 200526 485-490.

25 Rasmussen K, Moller J \& Lyngbak M. Within-person variation of plasma homocysteine and effects of posture and tourniquet application. Clinical Chemistry 199945 1850-1855.

26 Vermeulen A, Verdonck L \& Kaufman JM. A critica evaluation of simple methods for the estimation of free testosterone in serum. Journal of Clinical Endocrinology and Metabolism $1999 \mathbf{8 4}$ 3666-3672.

27 Sodergard R, Backstrom T, Shanbhag V \& Carstensen $H$. Calculation of free and bound fractions of testosterone and estradiol-17 beta to human plasma proteins at body temperature. Journal of Steroid Biochemistry and Molecular Biology $1982 \mathbf{1 6} 801-810$.

28 Ocke M, Bueno-De-Mesquita H, Pols M, Smit H, Van Staveren W \& Kromhout D. The Dutch EPIC food frequency questionnaire. II. Relative validity and reproducibility for nutrients. International Journal of Epidemiology 199726 49S-58S.

29 Stolk RP, Wink O, Zelissen PM, Meijer R, Van Gils AP \& Grobbee DE. Validity and reproducibility of ultrasonography for the measurement of intra-abdominal adipose tissue. International Journal of Obesity and Related Metabolic Disorders 200125 1346-1351.

30 Tornaghi G, Raiteri R, Pozzato C, Rispoli A, Bramani M, Cipolat $\mathrm{M} \&$ Craveri A. Anthropometric or ultrasonic measurements in assessment of visceral fat? A comparative study International Journal of Obesity and Related Metabolic Disorders 199418 771-775.

31 Voorrips LE, Ravelli AC, Dongelmans PC, Deurenberg P \& Van Staveren WA. A physical activity questionnaire for the elderly. Medicine and Science in Sports and Exercise 199123 974-979.

32 Cockcroft DW \& Gault MH. Prediction of creatinine clearance from serum creatinine. Nephron $19761631-41$.

33 Zmuda JM, Bausserman LL, Maceroni D \& Thompson PD. The effect of supraphysiologic doses of testosterone on fasting total homocysteine levels in normal men. Atherosclerosis $1997 \mathbf{1 3 0}$ 199-202.

34 Oktenli C, Yesilova Z, Ozata M, Yaman H, Tuzun A, Dundar S, Sanisoglu S, Musabak U, Erbil M \& Dagalp K. Gonadotropin treatment increases homocysteine levels in idiopathic hypogonadotropic hypogonadism: an indirect effect mediated by changes in body composition. Journal of Endocrinology 2003179 35-39.

35 Ueland PM \& Refsum H. Plasma homocysteine, a risk factor for vascular disease: plasma levels in health, disease, and drug therapy. Journal of Laboratory and Clinical Medicine 1989114 473-501.

36 Giri S, Thompson PD \& Taxel P. Oral estrogen improves serum lipids, homocysteine and fibrinolysis in elderly men. Atherosclerosis $1998137359-366$.

37 Sudhir K \& Komesaroff PA. Cardiovascular actions of estrogens in men. Journal of Clinical Endocrinology and Metabolism $1999 \mathbf{8 4}$ 3411-3415 
38 Sader MA, Mccredie RJ, Griffiths KA, Wishart SM, Handelsman DJ \& Celermajer DS. Oestradiol improves arterial endothelial function in healthy men receiving testosterone. Clinical Endocrinology 2001 54 175-181.

39 Komesaroff PA, Fullerton M, Esler MD, Dart A, Jennings G \& Sudhir K. Low-dose estrogen supplementation improves vascular function in hypogonadal men. Hypertension 200138 1011-1016.

40 Lew R, Komesaroff P, Williams M, Dawood T \& Sudhir K. Endogenous estrogens influence endothelial function in young men. Circulation Research 200393 1127-1133.

41 Dimitrova KR, Degroot KW, Pacquing AM, Suyderhoud JP, Pirovic EA, Munro TJ, Wieneke JA, Myers AK \& Kim YD. Estradiol prevents homocysteine-induced endothelial injury in male rats. Cardiovascular Research 200253 589-596.

42 Blouin K, Despres J-P, Couillard C, Tremblay A, Prud'homme D, Bouchard C \& Tchernof A. Contribution of age and declining androgen levels to features of the metabolic syndrome in men. Metabolism 200554 1034-1040.
43 Trivedi DP \& Khaw KT. Dehydroepiandrosterone sulfate and mortality in elderly men and women. Journal of Clinical Endocrinology and Metabolism 200186 4171-4177.

44 Martina V, Benso A, Gigliardi VR, Masha A, Origlia C, Granata R \& Ghigo E. Short-term dehydroepiandrosterone treatment increases platelet cGMP production in elderly male subjects. Clinical Endocrinology $2006 \mathbf{6 4} 260-264$.

45 Bostom AG, Jacques PF, Nadeau MR, Williams RR, Ellison RC \& Selhub J. Post-methionine load hyperhomocysteinemia in persons with normal fasting total plasma homocysteine: initial results from The NHLBI Family Heart Study. Atherosclerosis 1995116 147-151.

Received 28 May 2006

Accepted 28 September 2006 